NASA Technical Memorandum 102120

$$
\text { f }
$$

\title{
Simplified Procedures for Designing Adhesively Bonded Composite Joints
}

(HASA-TM-102120) SIMPLIFIED PKOCEDURES FOK DESIGNING ADHESIVELY BONDED COMPOSITE JOINTS (NASA. Lew is Research Center) 15 pCSCL 11D
N $89-26048$

Inclas

0219565

C.C. Chamis and P.L.N. Murthy

Lewis Research Center

Cleveland, Ohio

$2=$

Prepared for the

44th Annual Conference of SPI Composites Institute

Dallas, Texas, February 6-10, 1989

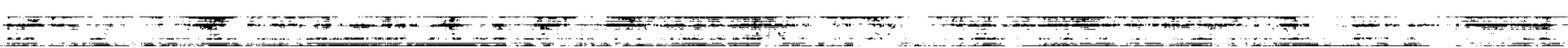


$\therefore=$

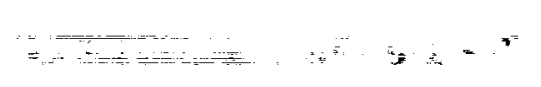


SIMPLIFIED PROCEDURES FOR DESIGNING ADHESIVELY BONDED COMPOSITE JOINTS

\author{
C.C. Chamis* and P.L.N. Murthyt \\ National Aeronautics and Space Administration \\ Lewis Research Center \\ Cleveland, Ohio 44135
}

\title{
SUMMARY
}

Procedures for the preliminary design of composite adhesive joints are described. Typical joints, their respective free body diagrams and approximate equations for estimating the stresses in each of these typical joints are summarized. Equations are also presented to check the critical conditions of the joint, such as: minimum length, maximum adhesive shear stress and peel-off stress. To illustrate the procedure, sample designs are described in step-bystep fashion for a butt joint with single doubler subjected to static loads, cyclic loads and environmental effects. The results show that (1) unsymmetric adhesive joints are inefficient and should be avoided, and (2) hygrothermal environments and cyclic loads dramatically reduce the structural integrity of the joint and require several joint lengths compared to those for static load with no environmental effects.

\section{INTRODUCTION}

The structural integrity of composite structures is often times determined by the integrity and durability of their respective joints. The two general classes of joints are mechanical fasteners and adhesive bonding. Both types of joints receive continuous attention in the fiber composites community. For example, ASTM Specialty Symposia are devoted to composite joints (ref. 1). Recent books on composites technology include chapters with extensive discussions (refs. 2 and 3 ) as well as entire books written on adhesively bonded joints (ref. 4). The discussions in these sources mainly deal with important details in composite joint design. No single source is available which summarizes step-by-step procedures for the preliminary design of composite joints.

It is generally accepted that the structural integrity of mechanical fastener joints mainly depends on the local laminate bearing strength while that for adhesively bonded joints mainly depends on local interlaminar shear strength. Recent research at NASA Lewis Research Center focused on developing simplified methods for predicting microstresses and local laminate strengths including interlaminar strengths (ref. 5). In a previous paper (ref. 6), these methods were used to design bolted composite joints. In the present paper these methods are used to design adhesively bonded joints for composite structures. The objective of the paper is to describe these methods and to outline a step-by-step procedure for the preliminary design of adhesively bonded joints. Numerical examples are included to illustrate applications to static loads and cyclic loads, including hot-wet service environments.

* Senior Aerospace Scientist, Structures Division.

†Aerospace Research Engineer, Structures Division. 


\section{ADHESIVE JOINT FUNDAMENTALS}

The fundamentals and terminology associated with adhesive joints are depicted schematically in figure 1. While only two different joints are shown in this figure, the notation and geometric dimensions are similar for all the different types of joints (figs. 2 and 3 ) to be considered in this design procedure.

The adherends and or doublers are identified by numerical subscripts while the adhesive is identified by the subscript a. All respective dimensions and stresses are identified by similar subscrlpts. The in-plane stress in the adherends is denoted by $\sigma_{i x x}$, for example, where $x x$ refers to the $x$-axis which is taken along the length of the joint.

The points to note in figure 1 are: (1) the stresses transfer from one adherend to adhesive and then to the other adherend, (2) these stresses increase very rapidly from the end and are highly nonlinear, (3) the estimates are obtained from simple shear-lag theory for minimum length $\ell^{\text {min }}$, maximum shear stress in the adhesive ogax, and maximum normal stress (peel-off stress) in the adhesive oghax.

The general steps for designing adhesive joints are as follows:

(1) Establish foint design requirements: loads, laminates, adhesive, safety factors and other special considerations.

(2) Obtain laminate dimensions and properties for the adherends using composite mechanics. (Typical properties needed for this procedure are summarized in tables I and II for three different laminates.)

(3) Obtain the properties of the adhesive. The adhesive will generally be the same as the matrix in the adherends. The specific properties needed are: (a) shear strength, and (b) peel-off strength.

(4) Degrade the adhesive properties for moisture, temperature and cyclic loads using the following equations.

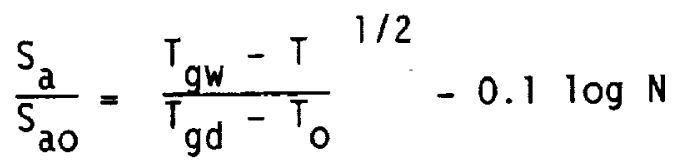

where $S_{a}$ is the expected adhesive strength being calculated for a particular loading environment; $S_{20}$ is the corresponding strength at reference conditions, usually taken as room temperature dry; $\mathrm{T}_{\mathrm{gw}}$ is the wet adhesive glass transition temperature given by

$$
T_{g w}=\left(0.005 M^{2}-0.1 M+1.0\right) T_{g d}
$$

where $M$ is the moisture in the adhesive in percent by weight and $T$ gd is the adhesive dry glass transition temperature, usually provided by the adhesive supplier; $T$ is the temperature of the joint at service conditions; $T_{0}$ is the reference temperature at which $S_{a 0}$ was determined, usually taken as 
room temperature; and $\mathrm{N}$ is the number of cycles which the joint must endure under the design stress.

(5) Select design allowables. These are either set by the design criteria or are chosen as follows: (a) a load factor on the force $F$ usually 1.5 or 2 , or (b) a safety factor of one-half of the degraded adhesive strength $S_{a}$ in step 4 above. The second alternative is preferable since the force $F$ may already contain a load factor.

(6) Select the length $\ell$ of the joint by using the following equation

$$
\ell=\frac{F}{S_{a s}}
$$

where $F$ denotes the load (tensile/compressive/shear) in the adherends per unit width and $S_{a s}$ denotes the design allowable shear stress in the adhesive.

(7) Check the minimum length and the maximum shear and normal stresses in the adhesive (using the shear-lag theory equations, fig. 1).

(8) Calculate the bending stresses in the doublers and adherends using respective equations from figures 2 and 3 .

(9) Calculate the margin of safety (MOS) for all calculated stresses. This is usually done at each step where stresses are calculated and compared to allowables using the following equation:

$$
\text { MOS }=\frac{\text { Allowable stress }}{\text { Calculated stress }}-1
$$

(10) Calculate the joint efficiency (J.E.) as follows:

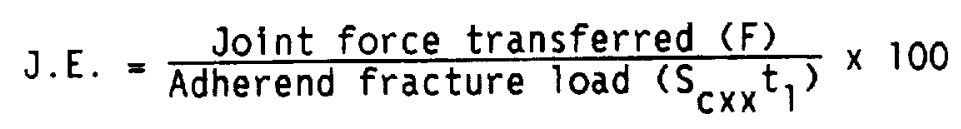

(11) Summarize joint design.

\section{BUTT JOINT WITH SINGLE DOUBLER AND NO ENVIRONMENTAL EFFECTS}

As an example, the step-by-step procedure will be used to design a joint with single doubler and no environmental effects.

(1) Joint design requirements:

Loads

specified $800 \mathrm{lb} / \mathrm{in}$. static load room temperature dry conditions

Laminate

$(0 / \pm 45 / 0 / 90)_{\mathrm{S}} \mathrm{T} 300 / \mathrm{E}$ at $0.6 \mathrm{FVR}, 0.05 \mathrm{in.}$ thick

Adhesive epoxy matrix same as in the laminate

Safety factors 1.0 on joint load; 0.5 on adhesive strengths 
(2) Laminate properties: typical predicted properties for this laminate are listed in tables I and II.

(3) Adhesive properties: typical predicted properties for structural epoxies are: $E=0.5 \mathrm{mpsi} ; G=0.18 \mathrm{mpsi} ; v=0.35 ; \alpha=30 \mathrm{ppm} /{ }^{\circ} \mathrm{F}$; $S_{a n}=15 \mathrm{ksi}$ and $S_{a s}=13 \mathrm{ksi}$.

(4) Environmental effects: none since the joint will be subjected to static loads at room temperature dry conditions.

(5) Design allowables: (a) joint load: $1 \times 800 \mathrm{lb} / \mathrm{in} .=800 \mathrm{lb} / \mathrm{in}$. , (b) adhesive normal or peel-off strength: $0.5 \times 15 \mathrm{ks} i=7.5 \mathrm{ks} \mathbf{i}$,

(c) adhesive shear strength: $0.5 \times 13 \mathrm{ksi}=6.5 \mathrm{ksi}$.

(6) Joint length:

$$
\begin{gathered}
\ell=\frac{F}{S_{a s}} \\
\ell=\frac{800 \mathrm{lb} / \mathrm{in} .}{6500 \mathrm{psi}}=0.12 \mathrm{in} .
\end{gathered}
$$

and the doubler length $=2 l=0.24 \mathrm{in}$.

(7) Check joint critical conditions (equations, fig. 1) minimum length = $0.7 \mathrm{t}_{\mathrm{a}}\left(\mathrm{E}_{\mathrm{cxx}} / \mathrm{G}_{\mathrm{a}}\right)^{1 / 2}$; (from ref. 4 assuming 0.99 load transfer efficiency) $t_{a}=$ 0.005 in., $E_{c x x}=10 \mathrm{mpsi}, G_{a}=0.18 \mathrm{mpsi}$.

$$
\begin{gathered}
\ell^{m i n}=0.7 \times 0.005 \mathrm{in} . \times \frac{10 \mathrm{mpsi}}{0.18 \mathrm{mpsi}}^{1 / 2} \\
e^{\min }=0.026 \mathrm{in} .<0.12 \mathrm{in} .
\end{gathered}
$$

Therefore, the joint length is $0.12 \mathrm{in}$. and the doubler length is $0.24 \mathrm{in}$. Use $1.0 \mathrm{in.} \mathrm{since} 0.25 \mathrm{in}$. is impractical for handling maximum shear stress concentration.

$$
\begin{gathered}
\sigma_{\mathrm{as}}^{\max }=3 \times \sigma_{\mathrm{as}} \\
\sigma_{\mathrm{as}}^{\max }=\frac{3 \times 800 \mathrm{lb} / \mathrm{in} .}{1 \mathrm{in}}=2400 \mathrm{ps} \mathbf{1} \\
2400 \mathrm{ps} i<6500 \mathrm{psi} 0 . \mathrm{K} . \\
\operatorname{MOS}=\frac{6500 \mathrm{ps} i}{2400 \mathrm{psi}}-1=1.71
\end{gathered}
$$


Peel-off stress (equation from figure 1):

$$
\begin{gathered}
\sigma_{\mathrm{an}}=\frac{3 \sigma_{1 \times x} t_{3}}{\ell+t_{3}} \\
\sigma_{\mathrm{an}}=\frac{3 \times 800 \mathrm{lb} / \mathrm{in} .}{1.0+0.05 \mathrm{in.}}=2286 \mathrm{psi} \\
2286 \text { psi<7500 psi } 0 . \mathrm{K} . \\
\text { MOS }=\frac{7500 \text { psi }}{2286 \text { psi }}-1.0=2.28
\end{gathered}
$$

Observations: (a) The joint length of $0.12 \mathrm{in}$. to meet design requirements was too small to be practical and was increased arbitrarlly to 1 in. which is a more practical dimension. The other critical conditions are satisfied with substantial margins indicating that single doubler butt joints are not generally efficient joints; (b) the joint length as calculated by the load transfer would be relatively small; and $(c)$ the foint length predicted by using shear lag is practically negligible indicating that the load transfer occurs in a very short distance.

(8) Bending stresses (equations, fig. 2)

Doubler:

$$
\sigma_{2 \times x t}=\frac{4 F}{t_{2}} ; \sigma_{2 \times \times C}=\frac{-2 F}{t_{2}}
$$

which is the same for the adherends as well.

$$
F=800 \mathrm{lb} / \mathrm{in} . ; \text { assume doubler is made from the same laminate as the }
$$

adherends

$$
\begin{gathered}
t_{2}=0.05 \mathrm{in} . \\
\sigma_{2 \times x t}=\frac{4 \times 800 \mathrm{ib} / \mathrm{in} .}{0.05 \mathrm{in} .}=64 \mathrm{ksi} \\
\sigma_{2 \times \times c}=-0.5 \sigma_{2 \times x \mathrm{t}}=-32 \mathrm{ksi}
\end{gathered}
$$

Comparing these stresses to corresponding fracture stresses in table II we see that

$$
\begin{aligned}
& 64 \mathrm{ksi}<79.2 \mathrm{ksi} 0 . \mathrm{K} \\
& 32 \mathrm{ksi}<79.7 \mathrm{ksi} \text { O.K. }
\end{aligned}
$$

(9) The corresponding MOS's are 
Tension:

$$
\operatorname{MOS}=\frac{79.2}{64}-1.0=0.24
$$

Compression:

$$
\operatorname{MOS}=\frac{79.7}{32}-1.0=1.49
$$

It is important to note that the laminate fracture stresses used for in-plane loads, are approximate and are appropriate for preliminary design. An improved estimate of these stresses is obtained by using laminate analysis to calculate the ply stresses. These calculations are generally expedited with the aid of ply stress influence coefficlents (ref. 5). For these laminates, the outer ply $\left(0^{\circ}-p l y\right)$ stress influence coefficients (ref. 5), which relate the ply material axes stresses to laminate structural axes stresses, are:

Load $\quad \sigma_{\ell 11} \quad \sigma_{\ell 22} \quad \sigma_{\ell 12}$

In-plane $\quad 1.993 \quad-0.007 \quad 0$

Bending $\quad 1.714 \quad-0.027 \quad-0.003$

The corresponding ply stresses are calculated by using the following equation

$$
\sigma_{\ell 11}=\frac{F}{t_{1}}(1.993+3 \dot{x} 1.714)
$$

where $F$ is the joint force and $t_{1}$ is the doubler thickness. Substituting respective values $F=800 \mathrm{lb} / \mathrm{in}$. and $t_{1}=0.05 \mathrm{in}$.

$$
\begin{aligned}
\sigma_{\ell 11} & =\frac{800 \mathrm{ib} / \mathrm{in} .}{0.05 \mathrm{in} .}(1.993+3 \times 1.714)=114.2 \mathrm{ksi} \\
\sigma_{\ell 22} & =\frac{800 \mathrm{ib} / \mathrm{in} .}{0.05 \mathrm{in} .}[-0.007+3 \times(-0.027)]=-1.41 \mathrm{ksi} \\
\sigma_{\ell 12} & =\frac{800 \mathrm{ib} / \mathrm{in} .}{0.05 \mathrm{in} .}[0.0+3 \times(-0.003)]=-0.41 \mathrm{ksi}
\end{aligned}
$$

Typical uniaxial ply strengths for this composite laminate are (ref. 5): longitudinal tension $S_{\ell 11 T}=220 \mathrm{ksi}$; transverse compression $\mathrm{S}_{\ell 22 \mathrm{C}}=35 \mathrm{ksi}$; and intralaminar shear $S_{212}= \pm 10 \mathrm{ksi}$. Comparing the calculated stresses in the outer play of the doubler to these strengths we have:

Longitudinal tension:

$$
\begin{aligned}
& 114.2 \mathrm{ksi}<220 \mathrm{ksi} 0 . \mathrm{K} . \\
& \text { MOS }=\frac{220}{114.2}-1.0=0.93
\end{aligned}
$$


Transverse compression:

$$
\begin{aligned}
& 1.41 \mathrm{ksi}<35.0 \mathrm{ksi} 0 . \mathrm{K} . \\
& \text { MOS }=\frac{35}{1.41}-1.0=23.8
\end{aligned}
$$

Intralaminar shear:

$$
\begin{aligned}
& 0.14 \mathrm{ksi}<10.0 \mathrm{ksi} 0 . \mathrm{K} . \\
& \text { MOS }=\frac{10.0}{0.14}-1.0=70.4
\end{aligned}
$$

As can be seen, the improved ply stress estimates result in an increased margin for $\sigma_{2 \times x t}$ indicating that the approximate approach (at least for this joint) is conservative.

(10) Joint efficiency - the joint efficiency is calculated from

$$
\text { J.E. }=\frac{F}{S_{\text {cxxt }}} \times 100=\frac{800 \mathrm{lb} / \mathrm{in} .}{79200 \times 0.05 \mathrm{psi} / \mathrm{in} .} \times 100=20 \text { percent }
$$

which is very poor. This poor efficiency is typical of all joints which induce bending in the doublers and in the adherends. The efficiency of this joint can be improved by selecting joints without bending (figs. 2 and 3 ), assuming the structure geometry permits it. Another way to improve the efficiency is to increase the thickness of both doubler and adherend at the joint which also increases fabrication complexity, time and cost.

(11) Joint design summary

Doubler

Laminate $(0 / \pm 45 / 90)$ s (same as adherends)

Composite T300/E (same as adherends)

Adhesive structural epoxy (same as epoxy in adherends)

Length $\quad \ell=1$ in. adjusted for fabrication handling 
Adhesive

Shear average

Shear maximum

Peel-off

Doubler/adherend

Combined-tension

Combined-compression

Joint efficiency, 20 percent

$$
\begin{array}{ccc}
\text { Calculated, } & \text { Allowable, } & \text { Margin of } \\
\sigma, & S, & \text { safety } \\
k s i & k s j &
\end{array}
$$

$\begin{array}{lll}0.8 & 6.5 & 7.12 \\ 2.4 & 6.5 & 1.71 \\ 2.3 & 7.5 & 2.28\end{array}$

$\begin{array}{lll}64 & 79.2 & 0.24 \\ 32 & 79.7 & 1.49\end{array}$

Comment: A joint without bending should be considered if the dimension and other design requirements permit it.

\section{BUTT JOINT WITH SINGLE DOUBLER IN A HYGROTHERMAL ENVIRONMENT}

AND UNDER CYCLIC LOAD

Redesign the joint considered in the previous section by assuming that the joint will be subjected to a hygrothermal environment of $150^{\circ} \mathrm{F}$ and 1 percent moisture by weight and must endure 10000 cycles of the design load.

Comment: Since the joint is the same as that designed without environmental effects, all that is needed now is to degrade the adhesive properties for environmental and cyclic load effects and repeat the calculations. We proceed by using the information in steps 1 to 3 and start with step 4 .

(4) Environmental effects: degrade adhesive properties for environmental and cyclic load effects.

Environmental effects:

$$
\begin{aligned}
& T_{g W}=\left(0.005 M^{2}-0.1 M+1.0\right) T_{g d}=\left[0.005(1.0)^{2}-0.1(1.0)+1.0\right] \times 420^{\circ} \mathrm{F}=378^{\circ} \mathrm{F} \\
& \frac{P}{P_{0}}=\left[\frac{T_{g W}-T}{T_{g d}-T_{0}}\right]^{1 / 2}-0.1 \log N=\left[\frac{378^{\circ} \mathrm{F}-150^{\circ} \mathrm{F}}{420^{\circ} \mathrm{F}-70^{\circ} \mathrm{F}}\right]^{1 / 2}-0.1 \log 10000=0.407
\end{aligned}
$$

and the degraded adhesive properties are

$S_{n} \quad 0.407 \times 15 \mathrm{ksi}=6.1 \mathrm{ksi}$

$\mathrm{S}_{\mathrm{s}} \quad 0.407 \times 13 \mathrm{ksi}=5.3 \mathrm{ksi}$

$\mathrm{G}_{\mathrm{a}} \quad 0.407 \times 0.18 \mathrm{mpsi}=0.07 \mathrm{mpsi}$ 
(5) Adhesive allowable stresses: the allowable stresses in the adhesive are 50 percent of those degraded above or

San $3.05 \mathrm{ksi}$.

Sas $2.65 \mathrm{ksi}$

(6) Select joint length:

$$
\begin{gathered}
\ell=\frac{F}{S_{a s}} \\
\ell=\frac{800 \mathrm{lb} / \mathrm{in} .}{2650 \mathrm{ps}}=0.3 \mathrm{in} .
\end{gathered}
$$

The length of the doubler is $2 l$ or about $0.6 \mathrm{in}$. which is 2.5 times greater than that used without environmental and cyclic loading. Use 1 in. for the same reasons mentioned earlier.

(7) Check joint critical conditions: the equations to check the critical conditions are in figure 1 . The values need are: $E_{c x x}=10 \mathrm{mpsi}, G_{a}=$ $0.07 \mathrm{mpsi}$ and $t_{\mathrm{a}}=0.005 \mathrm{in.} ; \mathrm{P}_{\min }=0.70 \mathrm{t}_{\mathrm{a}}\left(\mathrm{E}_{\mathrm{cxx}} / \mathrm{G}_{\mathrm{a}}\right)^{1 / 2}=0.7 \times 0.005$ $x(10 \mathrm{mpsi} / 0.07 \mathrm{mpsi})^{1 / 2}=0.042 \mathrm{in}$.

$$
0.042 \text { in. }<0.3 \text { in. O.K. }
$$

The maximum shear stress is

$$
\begin{aligned}
\sigma_{\mathrm{as}}^{\max }=\frac{3 \mathrm{~F}}{\ell} & =\frac{3 \times 800 \mathrm{lb} / \mathrm{in} .}{1.0}=2400 \mathrm{psi} \\
2400 \mathrm{psi}<2650 \mathrm{psi} 0 . \mathrm{K} . & \\
M O S= & \frac{2650 \mathrm{psi}}{2400 \mathrm{psi}}-1.0=0.1
\end{aligned}
$$

The maximum normal stress in the adhesive is

$$
\begin{gathered}
\sigma_{\mathrm{an}}^{\max }=\frac{3 \mathrm{~F}}{\ell+t_{1}}=\frac{3 \times 800 \mathrm{lb} / \mathrm{in} .}{(1.0+0.05) \mathrm{in} .}=2285 \mathrm{psi} \\
2285 \mathrm{psi}<3050 \mathrm{psi} 0 . \mathrm{K} . \\
\text { MOS }=\frac{3050 \mathrm{psi}}{2285 \mathrm{ps} i}-1.0=0.33
\end{gathered}
$$

(8) Bending stresses: the bending stress in the doubler will be the same as in the previous section. The laminate allowables will not change. However, the improved estimates based on ply properties must be calculated by degrading the resin dominated ply properties (ref. 5). 
Observations: (a) environmental and cyclic load effects degrade joint integrity substantially as seen in the reduction of MOS, (b) joint lengths are substantially greater; however, well within the design lengths, and (c) the bending stresses are generally not affected if $0^{\circ}$ plies are placed adjacent to the adhesive in both doubler and adherends since fiber dominated properties are not sensitive to moisture and temperature.

\section{DISCUSSION}

The design of composite adhesive joints requires attention to all joint details. The two sample cases illustrate the steps to be followed for the preliminary design of these joints. Though the sample cases were limited to only a butt joint with a single doubler, the steps for the joints summarized in figures 2 and 3 are the same as is the procedure for accounting for environmental and cyclic load effects.

Preliminary designs based on the procedure outlined herein must be backed up by suitable finite element analysis. A unit width model with plane elements through the adherend and adhesive thickness is usually sufficient. The finite element model should have sufficient length to simulate the bending in the case of unsymmetric joints. Once the joint design has been finalized, the design must be verified by strategically selected experiments. Composite joints with induced bending (figs. 2 and 3 ) should be avoided since these joints are not efficient with respect to load transfer. Wherever possible design requirements should be adjusted to avoid unsymmetric joints.

\section{CONCLUSIONS}

Design procedures of composite adhesive joints have been described. The equations governing the design of several typical joints are summarized. Two sample designs are carried out in detail to demonstrate the step-by-step design procedures. One of these sample designs is for joints under static load and no environmental effects while the other includes the effect of hygrothermal environments and cyclic load. The results of these two sample cases show that (1) unsymmetric joints are inefficient and should be avoided and (2) environmental and cyclic loading require joint lengths which are several times those without these effects.

\section{REFERENCES}

1. K.T. Kedward, Editor, Joining of Composite Materials, ASTM STP-749, American Society for Testing and Materials, Philadelphia, PA, 1981.

2. G. Lubin, Editor, Handbook of Composites, van Nostrand Reinhold Co., New York, 1982, Chapter 22.

3. B.C. Hoskins and A.A. Baker, Editors, Composite Materials for Aircraft Structures, AIAA, New York, NY, 1985, Chapter 8.

4. R.D. Adams and W.C. Wake, Structural Adhesive Joints in Engineering, Elsevier Applied Science Publishers, New York, 1984. 
5. P.L.N. Murthy and C.C. Chamis, ICAN: Integrated Composite Analyzer, J. Compos. Technol. Research, vol. 8, no. 1, 1986, pp. 8-17. (Al so NASA TP-2515, 1986.)

6. C.C. Chamis, "Simplified Procedures for Designing Composite Bolted Joints," NASA TM-100281, 1988.

TABLE I. - PREDICTED LAMINATE PROPERTIES ${ }^{a}$

[T300/E at 0.6 FVR.]

\begin{tabular}{|c|c|c|c|}
\hline Property type & $(0 / \pm 45 / 0 / 90)_{S}$ & $\left(0_{3} / \pm^{80}\right)_{S}$ & $\left(0 /+30 / b_{0} \mathrm{~s} /-30 / 0\right)_{\mathrm{S}}$ \\
\hline$E_{C x x}$, mpsi & 10.0 & 12.5 & 12.8 \\
\hline$E_{\text {cyy }}$, mpsi & 6.5 & 8.3 & 1.7 \\
\hline$E_{c z z}$, mpsi & 1.4 & 1.4 & 1.5 \\
\hline$G_{c x y}$, mpsi & 2.4 & 7.9 & 2.0 \\
\hline$G_{c y z}, \operatorname{mps} i$ & .43 & .43 & .39 \\
\hline$G_{c x z}$, mpsi & .48 & .48 & .59 \\
\hline$v_{c x y}$ & .31 & .06 & .91 \\
\hline${ }^{{ }}$cyz & .32 & .38 & .36 \\
\hline${ }^{v} \mathrm{cxz}$ & .26 & .36 & $\sim 0$ \\
\hline$\alpha_{c x x}, \mu i n . / i n . /^{\circ} \mathrm{F}$ & .41 & .53 & -.53 \\
\hline$\alpha_{\text {cyy, min./in. } /{ }^{\circ} \mathrm{F}}$ & 1.5 & 1.3 & 10.1 \\
\hline$\alpha_{\mathrm{CZZ}}$, $\mu$ in./in. $/^{\circ} \mathrm{F}$ & 20.1 & 20.1 & 16.3 \\
\hline
\end{tabular}

a ICAN (ref. 5).

$b_{0} S$ denotes S-G/E ply.

TABLE II. - PREDICTED FRACTURE STRESSES FOR SELECT LAMINATES ${ }^{\mathrm{a}}$

[T300/E at 0.60 FVR. $S_{C}=1$ aminate strength;

$x, y, z=$ direction $(x, y=1$ aminate plane

and $z=$ thickness); $T, C, S=$ tension,

compression, shear.]

\begin{tabular}{|c|c|c|c|}
\hline $\begin{array}{c}\text { Stress } \\
\text { type }\end{array}$ & $(0 / \pm 45 / 0 / 90)_{S}$ & $\left(0_{3} / \pm 80\right)_{S}$ & $\left.0 /+30 /{ }^{b}{ }^{S} /-30 / 0\right)_{S}$ \\
\hline$S_{\text {CXXT }}$ & 79.2 & 94.8 & 129.3 \\
$S_{\text {CXXC }}$ & 79.7 & 99.1 & 70.5 \\
$S_{\text {cyyT }}$ & 49.8 & 61.0 & 6.3 \\
$S_{\text {CyyC }}$ & 51.5 & 67.8 & 14.7 \\
$S_{\text {CxyS }}$ & 38.7 & 13.7 & 20.0 \\
$S_{\text {CzyS }}$ & 21.8 & 21.8 & 21.8 \\
\hline
\end{tabular}

$a_{\text {ICAN (ref. 5). }}$

$b_{0} S$ denotes S-G/E ply. 

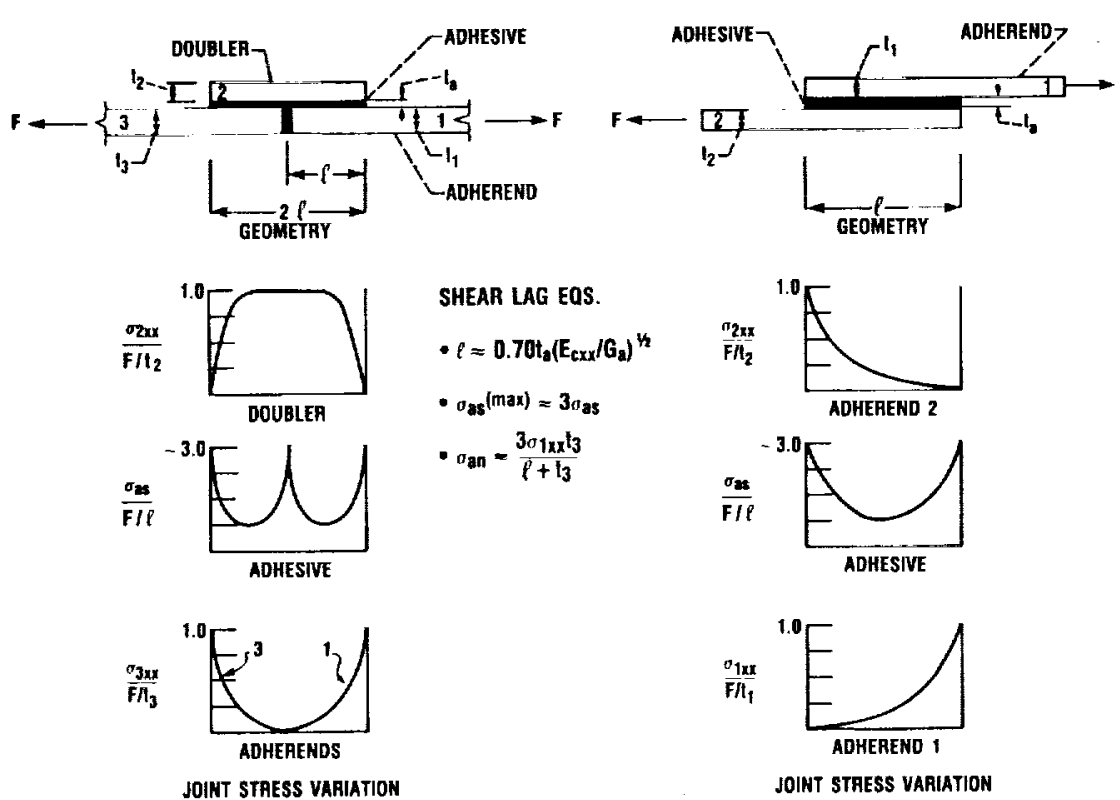

JOIHT STAESS VARIATION

FIGURE 1. - ADHESIVE JOINT DEFIHITIONS AND FUNDANENTALS.

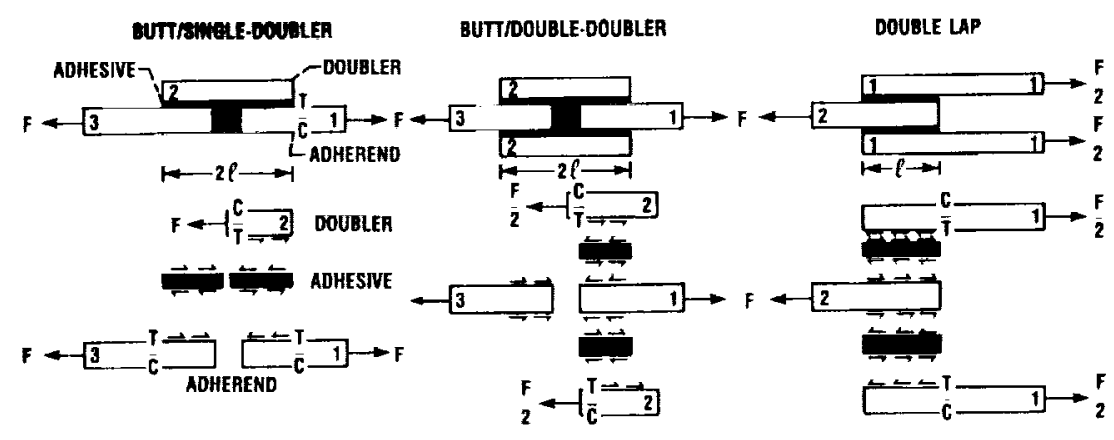

DOUBLER:

\begin{tabular}{|c|c|c|}
\hline$\sigma_{2 \times \mathrm{T}, \mathrm{C}}=4 F / I_{2},-2 F / I_{2}$ & $\sigma_{2 \times \mathrm{KT}, \mathrm{C}}=2 \mathrm{~F} \mathbf{I}_{2},-F h_{2}$ & $\sigma_{1 \times x T, C}=4 F / t_{1},-2 F / t_{1}$ \\
\hline $\begin{array}{l}\text { ADHESIVE: } \\
\qquad \begin{aligned} \sigma_{n} & =F / \ell \\
\sigma_{a n} & =3 F /\left(l+l_{1}\right)\end{aligned}\end{array}$ & $\begin{array}{l}\sigma_{\mathrm{as}}=F / 2 \uparrow \\
\sigma_{\mathrm{an}} \approx 3 F\left(f+I_{2}\right)\end{array}$ & $\begin{array}{l}\sigma_{3}=F / 2 \ell \\
\sigma_{2 A}=3 F /\left(P+l_{1}\right)\end{array}$ \\
\hline $\begin{array}{l}\text { ADHEREND: } \\
\qquad \begin{array}{r}\sigma_{1 \times X T, C}=4 F / I_{1},-2 F / I_{1} \\
\sigma_{3 \times x, C}=4 F / I_{3},-2 F / I_{3}\end{array}\end{array}$ & $\begin{array}{l}\sigma_{1 \times x T}=F / h_{1} \\
\sigma_{3 \mathrm{XXT}}=F / I_{3}\end{array}$ & $\sigma_{2 x \times T}=F / t_{2}$ \\
\hline
\end{tabular}

FIGURE 2. - SCHEMATICS OF CONWONLY USED ADHESIVE JOINTS (FREE BODY DIAGRAMS AND GOVERNIng EQUATIONS). 


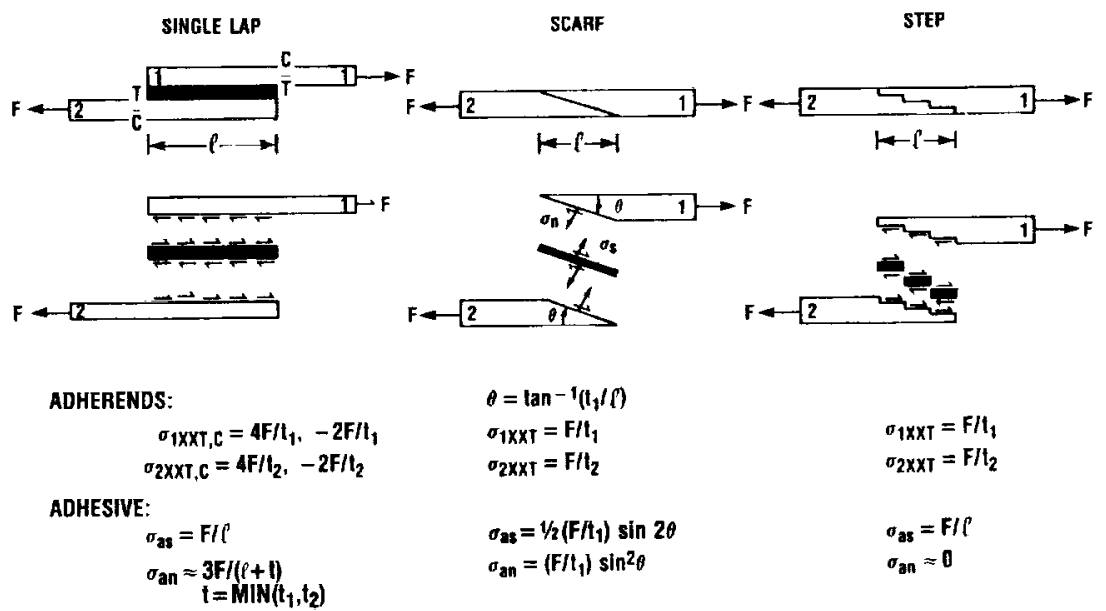

FIGURE 3. - SCHEMATICS OF COMMONLY USED ADHESIVE JOINTS CONTINUED (FREE BODY DIAGRAMS AND GOVERNING EQUATIONS). 


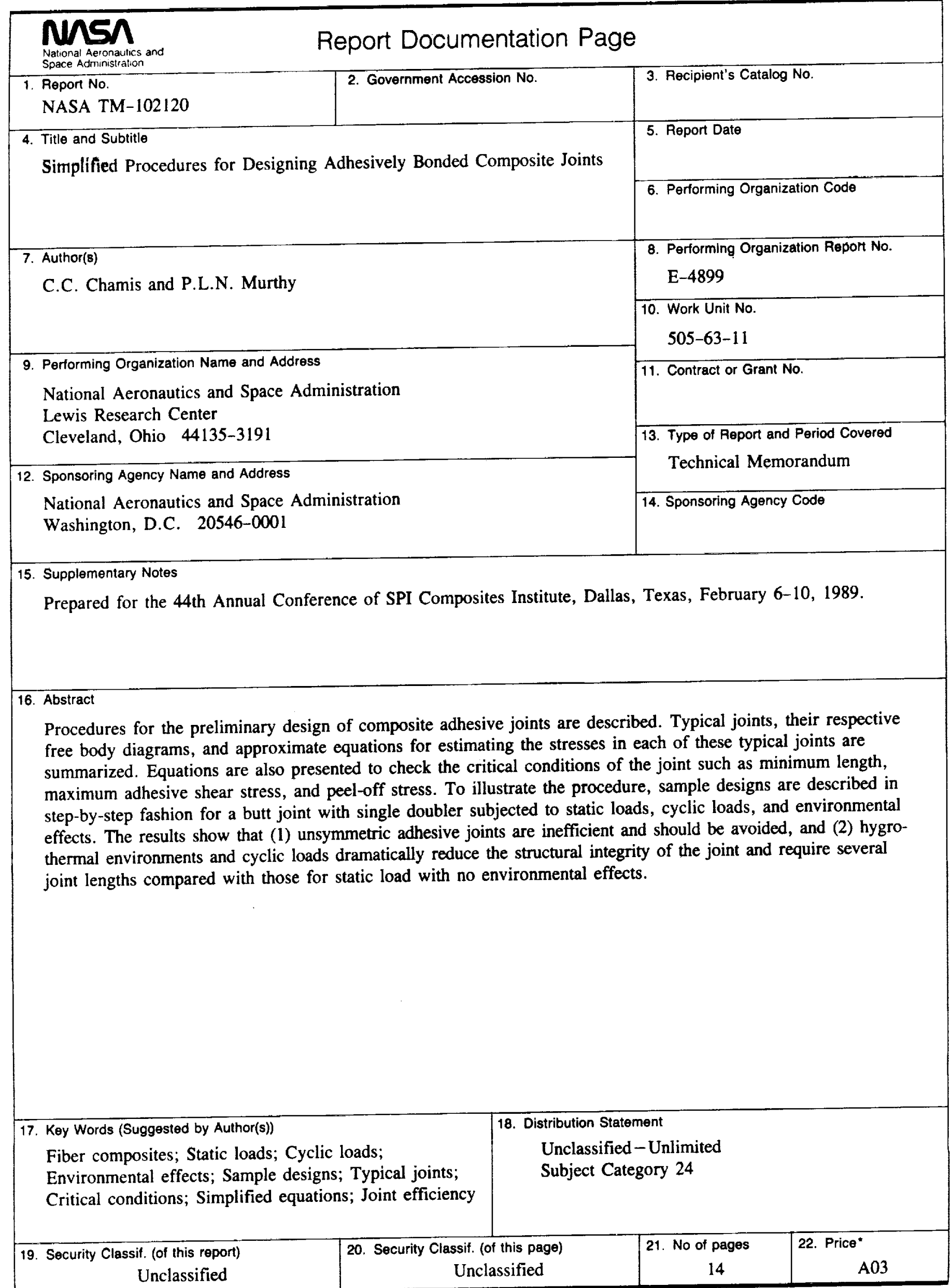

